\title{
(Algunes) variacions sobre el diable: una proposta de catalogació de dues llegendes satàniques
}

\author{
Emili Samper Prunera \\ Universitat Rovira i Virgili \\ emili.samper@urv.cat
}

\begin{abstract}
RESUM
En el marc del projecte «RondCat: rondalles catalanes», dirigit per Carme Oriol i Josep M. Pujol, i la catalogació de rondalles que no tenen correspondència a l'índex internacional d'Aarne-Thompson-Uther [ATU], es proposa la creació de dos tipus nous: C-Io3 («Dimoni, on vas?») i C-II3 (La fondària del gorg). El punt de partida és l'estudi de la llegenda satànica fet per Josep M. Pujol l'any I994 ( "Variacions sobre el diable»), així com el corpus recollit pel folklorista Cels Gomis i Mestre (I84I-I9I5). La proposta de creació dels dos tipus inclou la relació de les versions catalanes localitzades fins al moment.
\end{abstract}

PARAules ClAu

Cels Gomis i Mestre; RondCat; llegenda; tipus; classificació

\begin{abstract}
In the framework of the project 'RondCat: Catalan Folktales', directed by Carme Oriol and Josep M. Pujol, and the classification of folktales which have no corresponding type entry in the Aarne-Thompson-Uther international index [ATU], the present article proposes the creation of two new types: C-IO3 ('Devil, where are you going?) and C-II3 (The depth of the pool). The article bases this proposal on Josep M. Pujol's study of satanic legends in 1994 ("Variacions sobre el diable") and on the tales collected by the folklorist Cels Gomis i Mestre (I84I-I9I5). The proposed creation of the two new types includes a description of the Catalan versions that have been found to date.
\end{abstract}

KEYWORDS

Cels Gomis i Mestre; RondCat; legend; type; classifying

REBUT: OI.07.2OI5 | ACCEPTAT: 30.07.20I5

Estudis de Literatura Oral Popular, núm. 4, 2OI5, IO7-I2O | DOI: Io.I7345/elop20I5IO7-I2O

ISSN: 2OI4-7996 | http://revistes.urv.cat/index.php/elop 


\section{Introducció ${ }^{1}$}

L'any I994 Josep M. Pujol va publicar a les pàgines de la Revista d'etnologia de Catalunya un treball titulat «Variacions sobre el diable» centrat en l'estudi de les estructures de la llegenda satànica, així com en les afinitats entre els mons satànic i demònic i la dimensió moral del diable. ${ }^{2}$ A partir d'un corpus textual determinat, format per reculls rondallístics (com els que anys més tard catalogaria, amb Carme Oriol, a l'Índex tipològic de la rondalla catalana, en català [2003] i en anglès [2008]) i també llegendístics, Josep M. Pujol presentava les estructures d'aquests tipus de relats protagonitzats pel diable, tan interessants precisament per la seva variabilitat. Seguint aquest mateix esperit, i agafant com a punt de partida els corpus i els criteris emprats per Pujol, en aquest article centro la meva atenció en dos d'aquests relats en particular, a partir de les versions recollides pel folklorista Cels Gomis i Mestre. A partir d'aquestes versions, de les que apuntava Pujol en el seu estudi i de les que he localitzat, proposo la creació de dos nous tipus, en el marc del projecte «RondCat: rondalles catalanes», que han de servir per a catalogar aquestes (i altres) versions d'aquests dos relats.

\section{La narrativa folklòrica de Cels Gomis}

Nascut el I84I a Reus i mort a Barcelona fa tot just cent anys (I9I5), Cels Gomis i Mestre és un autor molt interessant amb una prolífica obra que abraça àmbits tan diversos com són el folklore i l'excursionisme, la política, la pedagogia i la literatura (Samper 2013 $b$ ). La seva ideologia progressista (fruit del seu pensament anarquista) es pot resseguir en tota la seva obra. Una part important d'aquesta, que és també la més coneguda, és la que se centra en el seu interès pel folklore i està formada per articles i reculls on hi podem trobar relats, parèmies, endevinalles, etc. Aquesta obra folklòrica es pot dividir en dos grans blocs: els articles (eminentment excursionistes) en els quals el folklorista inclou mostres diverses inserides dins les explicacions detallades d'excursions per tot el territori que trepitja; i els estudis monogràfics centrats, ara sí, en diferents mostres de folklore, organitzats temàticament i dedicats, per exemple, a la meteorologia, les plantes, els animals i les bruixes.

Una part d'aquesta obra folklòrica està formada per rondalles i llegendes. Tot i que en cap dels dos casos (especialment en les rondalles) Cels Gomis presenti cap recull dedicat específicament a un d'aquests dos gèneres narratius, les rondalles i les llegendes que trobem en la seva obra es poden estudiar i comparar amb altres versions coincidents d'acord amb els catàlegs existents. Així, les seves rondalles es troben editades, catalogades i estudiades en un volum recent, Les rondalles de Cels Gomis i Mestre (Samper 2OI5), que recull les que es poden classificar segons l'índex internacional de tipus d'Aarne-Thompson-Uther [ATU]. Les rondalles (i també les llegendes) que no es poden classificar segons aquest índex van ser objecte d'estudi d'una part de la meva tesi doctoral (Samper 20I3a). A partir d'aquest primer intent de classificació d'aquests materials que formen la narrativa folklòrica de

I. Aquest article s'emmarca en una línia d'investigació sobre literatura popular catalana que ha rebut finançament del Ministeri d'Economia i Competitivitat a través del projecte d'R+D: FFI2OI2-3I808, i forma part de la investigació del Grup de Recerca Identitats en la Literatura Catalana (GRILC), consolidat per la Generalitat de Catalunya (2OI4 SGR 755).

2. El text està inclòs dins l'obra folklòrica de Josep M. Pujol (Oriol-Samper 20I3: 289-306). 
Cels Gomis, proposo ara l'estudi particular de dos d'aquests relats amb la creació de dos tipus nous, que s'emmarquen dins el projecte de catalogació de rondalles catalanes RondCat.

\section{El projecte RondCat i els tipus no inclosos al catàleg internacional de tipus rondallístics}

El projecte «RondCat: rondalles catalanes», creat i dirigit per Carme Oriol i Josep M. Pujol del Departament de Filologia Catalana de la Universitat Rovira i Virgili, se centra en l'estudi de les rondalles catalanes i té per triple objectiu la catalogació, l'estudi i la difusió de les rondalles de tradició oral recollides en llengua catalana en tota la seva àrea lingüística (Catalunya, Franja d'Aragó, Catalunya del Nord, Andorra, Mallorca, Menorca, Eivissa, Formentera, País Valencià, el Carxe i l'Alguer).

És un projecte de llarg recorregut, a causa de la gran quantitat de dades que s'han considerat, i s'ha dut a terme en diferents fases. ${ }^{3}$ Entre els anys 2000-2002 i 2005-2007 va estar finançat pel Centre de Promoció de la Cultura Popular i Tradicional Catalana del Departament de Cultura de la Generalitat de Catalunya (a través de diversos contractes de prestació de serveis) i per la Universitat Rovira i Virgili (a través del programa de Tècnics de Suport a la Recerca i del programa dedicat a Projectes d'Innovació Docent).

L'abast temporal és el període que va des del I853, data de l'edició del primer recull de rondalles catalanes, obra de Manuel Milà i Fontanals, fins a l'actualitat. Els resultats de la recerca duta a terme han estat la publicació de l'Índex tipològic de la rondalla catalana (Oriol-Pujol 2003), la publicació de l'Index of Catalan Folktales (Oriol-Pujol 2008) que és la versió anglesa (modificada i ampliada en un 25\% respecte la versió catalana), publicada a la prestigiosa col-lecció Folklore Fellows' Communications de l'Acadèmia de Ciències Finlandesa (Suomalainen Tiedeakatemia) que acull els treballs d'aquest tipus. El llibre, a part del valor estrictament acadèmic, es proposa reivindicar el paper internacional de la cultura catalana com a cultura específica. Així, conté una introducció destinada a un públic internacional on s'explica l'àrea lingüística i cultural catalana i la recerca rondallística feta als Països Catalans. També presenta, per a cada tipus rondallístic, el número de catalogació (seguint l'índex ATU), un títol genèric, un resum de l'argument i les referències bibliogràfiques organitzades per regions.

El tercer resultat d'aquest projecte és la creació del web «RondCat: cercador de la rondalla catalana» <http://rondcat.arxiudefolklore.cat> que pretén posar a disposició dels estudiosos i del públic en general, una eina que faciliti l'accés a les dades sobre les rondalles d'una forma ràpida, pràctica i permanentment actualitzada. El web, consultable en quatre llengües (català, anglès, espanyol i francès), ofereix una completa informació introductòria sobre la catalogació de les rondalles en l'àmbit internacional, així com sobre la recol-lecció duta a terme a les terres de llengua catalana i el projecte de catalogació realitzat al mateix RondCat.

Si els dos primers resultats del projecte (Oriol-Pujol 2003 i 2008) se centren en les rondalles catalanes que es poden catalogar segons l'índex internacional ATU,

3. Per als detalls del projecte, vegeu Oriol-Pujol (2002; 2003; 2008) i la base de dades RondCat. 
el cercador RondCat amplia el seu objecte d'estudi a aquelles rondalles que no es poden classificar segons aquest índex. És en aquests casos en els quals se segueix una classificació pròpia per a aquells relats que es poden agrupar sota un nou tipus. Aquests nous tipus apareixen al cercador RondCat encapçalats per la lletra «C», que indica que es tracta d'un tipus documentat en l'àmbit lingüístic català, seguida d'un número. Aquesta numeració es dóna a les rondalles documentades en més d'una versió i és estrictament correlativa.

\section{La proposta de nous tipus}

Josep M. Pujol identifica a «Variacions sobre el diable» diferents relats i els relaciona amb el mode demònic. Segons Pujol, «La funció principal d'una gran part d'aquests relats consisteix en la sublimació del terror satànic [satanic dread] al marge del discurs teològic oficial, de manera no gaire diferent de com la llegenda urbana sublima els terrors actuals» (Pujol I994: 44; 20I3: 289).

D'entre tots els arguments recollits per Pujol, a partir de les versions examinades, n'he seleccionat dos per a proposar la creació de dos nous tipus «C»: els números C-IO3 («Dimoni, on vas?») i C-II3 (La fondària del gorg). En tots dos casos he localitzat versions presents a l'obra del folklorista Cels Gomis i també en altres reculls catalans que no apareixen en l'estudi de Pujol. Considero que la seqüència d'episodis i motius d'aquests relats justifica la seva creació com a tipus.

Per a les versions catalanes d'altres reculls assenyalades en aquests tipus nous, he tingut en compte, inicialment, el corpus inclòs a Oriol-Pujol i al RondCat. ${ }^{4}$ L'he ampliat, seguint el model de Pujol (I994: 46-47; 20I3: 292-293), amb l'escorcoll de col-leccions llegendàries i de treballs apareguts en revistes o, fins i tot, manuscrits. ${ }^{5}$ En moments puntuals, he afegit la referència a versions reelaborades literàriament (com les d'Apel.les Mestres) per la seva coincidència argumental amb els tipus proposats o algunes versions concretes de Gomis. ${ }^{6}$

Les versions que formen aquests tipus nous que proposo no són, de fet, rondallístiques. Això és així, tenint en compte, d'una banda, el corpus examinat per Pujol (centrat en l'estructura de la llegenda satànica) així com la naturalesa del corpus narratiu folklòric de Gomis que he utilitzat com a base per a crear els nous tipus.7 Segueixo aquest criteri d'acord amb el mateix projecte «RondCat: rondalles catalanes» que preveu l'agrupament dels nous tipus «C» per gèneres narratius. ${ }^{8}$ Les versions d'aquests nous tipus proposats les podem classificar (tenint en compte el gènere), com a llegendes satàniques. Segons Heda Jason (2000: I46), la llegenda satànica pertany al mode satànic en què l'ésser humà es relaciona amb el poder del diable i s'hi enfronta, dins el context de la lluita entre Déu i Satanàs.

\footnotetext{
4. Sobre la tria d'aquests reculls, vegeu Oriol-Pujol (2002; 2003: I2-I3/38I-388; 2008: I5I7/304-3I3) i la base de dades RondCat.

5. És el cas del manuscrit del fons Milà i Fontanals de Santander sobre supersticions i costums populars editat per Joan-Antoni Paloma (I976).

6. Tenint en compte, això sí, que aquestes versions reelaborades no s'han d'incorporar al RondCat, que només inclou versions de procedència oral.

7. Analitzat amb detall a Samper (20I3a: I7I-I9I; 447-452).

8. Cal tenir present, en aquest sentit, que els tipus de l'índex internacional ATU no inclouen únicament textos rondallístics, ja que la catalogació per arguments ho propicia.
} 
En aquests dos tipus nous assenyalo el número assignat (correlatiu respecte els anteriors presents al RondCat), un títol genèric (assignat per mi), els motius presents en l'argument (seguint Thompson I955-58), seguits de l'argument del tipus (un resum representatiu) i de la llista de versions que he localitzat i que, al meu parer, permeten crear el nou tipus. Per a cada versió assenyalo la referència bibliogràfica (any i pàgina on apareix el relat) i, si en té, el títol.

En annex he inclòs les versions de Gomis de les quals parteixo per a crear els nous tipus. En la llista de versions de cada tipus, remeto a aquests textos. He utilitzat l'edició més recent dels textos i he actualitzat l'ortografia i he normalitzat la puntuació d'acord amb els criteris actuals en les versions prenormatives. En les notes a peu de pàgina, encapçalo amb «GoMIs]» les que són del propi autor i, després de la cita, en dono la procedència. Ordeno cronològicament les diferents versions de cada tipus i les numero per a facilitar-ne la identificació. Totes inclouen un títol descriptiu assignat per mi i escrit entre claudàtors a l'inici, immediatament abans de la indicació de la seva procedència.

\subsection{Tipus C-103: «Dimoni, on vas?»}

\section{Motius:}

G303.3.3.I.6. Devil in form of goat; G303.4.7. Devil speaks with voice of a he-goat.

\section{Resum:}

Un home es troba una cabra i se l'emporta cap a casa carregada al coll. Quan passa prop d'un torrent, se sent una veu que crida: «Dimoni, on vas?» i la cabra respon: «A cavall d'en Jaumàs». L'home deixa la cabra i marxa corrents.

\section{Versions:}

- Alsina-Jubany (I988: I9);

- Arxiduc (I895: I25-I28) «Es dimonis boyets de Son Martí»;

- Coll Monteagudo (20I2: 54) «La roca del Diable»;

- Ferrer (2009: 48) «Li surt el dimoni»;

- Gomis (I9IO: 96-97; 20I4: IO2-IO3) [Annex I.I];

- Gomis (I987: 94) [Annex I.2];

- Gomis (I987: 94) [Annex I.3];

- Gomis (I987: 95) [Annex I.4];

- Mestres (I933: 29; 2004: 42-43) «El cabrit negre»;

- Roviró (2000: 43-44) núm. 33 «En Marfà»;

- Serra i Boldú (I932: 86) «La cabra. Tradicions, llegendes i supersticions»;

- Verdaguer (I992: I4O-I43; 2003: 58I-583) «No furtaràs».

Proposo la creació d'aquest nou tipus a partir de quatre versions que Gomis recull d'aquesta llegenda satànica en què apareix el dimoni (el mateix Satanàs o un dimoni xic) en forma de cabra a lloms d'un mortal que la deixa anar i fuig corrents quan la sent parlar. En aquestes versions no es fan explícites les intencions del protagonista, tot i que és molt probable que coincideixin amb les que assenyala Pujol (I994: 5I; 20I3: 296-297): vendre la cabra o menjar-se-la. 
En les tres primeres versions, l'acció té lloc en un espai concret que es coneix amb un nom que deixa clar la seva relació amb el diable. Així, ens trobem amb la «gorga nomenada del Dimoni» (versió I.I), «un lloc anomenat gorg dels Dimonis» (versió I.2) i «la roca del Diable» (versió I.3). En les versions I.I i I.3 qui pren la forma de l'animal és un dimoni i un dimoni xic, mentre que en la versió I.2 és el mateix Satanàs. En la versió I.4 no s'especifica. Per a desfer-se del dimoni, el protagonista recorre en dues de les versions (I.I i I.2) a les «témpores de sant Tomàs». Pel que fa als animals, ens trobem davant d'una cabra (versions I.I i I.4), una cabra negra (versió I.3) i un cabró (versió I.2).

Per a la resta de versions catalanes assenyalades, parteixo de les aportacions que fa Pujol en el seu estudi sobre la llegenda satànica i les amplio, fins a un total de dotze versions (incloses les ja citades de Gomis i les dues reelaboracions literàries de Mestres i Coll Monteagudo). Dos dels relats estudiats per Pujol (I994: 5I; 2013: 296-297) segueixen aquesta mateixa estructura, com assenyalo a les versions. Es tracta d'una versió d'Apel-les Mestres (I934: 29; 2002: 42-43), titulada «El cabrit negre» i una de Verdaguer (I992: I4O-I43; 2003: 58I-583), que porta per títol «No furtaràs».

Totes les versions comparteixen els trets essencials descrits al resum, amb petites variacions al diàleg, sempre en forma rimada. La versió d'Alsina-Jubany (I988: I9) té lloc a Dosrius (en el trajecte cap a Llinars) i coincideix, d'aquesta manera, amb la versió I.3 de Gomis. Pujol (I994: 5I; 20I3: 296-297) observa com aquests relats també són presents en versions mallorquines. A diferència de les versions de Catalunya, a Mallorca són els dimonis boiets els que prenen la forma de cabrits, i no pas Satanàs o un dimoni. És el que trobem a la versió de l'Arxiduc (I895: I25I28). A Ferrer (2009: 48), però, sí que hi apareix el dimoni. Aquesta versió té la particularitat d'estar protagonitzada pel comte Mal, personatge llegendari en terres mallorquines. Roviró (2000: 43-44) recull la seva versió de Joanet Faja (el I9 de juliol de I986, a Vinyoles d'Orís) i la situa al gorg Negre. La versió de Serra i Boldú (I932: 86) és exacta a la versió I.I de Gomis. Tenint en compte que el folklorista reusenc se cita com a font en aquest mateix article (de I932), és probable que Serra i Boldú utilitzi directament aquesta versió de la Zoologia popular de Gomis (de I9IO). En la versió de Verdaguer (I992: I4O-I43; 2003: 58I-583), el protagonista està acompanyat per la seva dona i agafa el cabrit perdut amb la intenció «pecaminosa» de menjar-se'l. La veu és del mateix Satanàs, com indica Pujol (I994: 5I; 20I3: 296-297).

Pel que fa a les versions literàries, en la de Mestres (I933: 29; 2004: 42-43), el protagonista està acompanyat per la seva dona i agafa la cabra amb la intenció de vendre-la. La veu és d'un dimoni xic, com assenyala Pujol (I994: 5I; 20I3: 296297), i el trajecte que vol fer el protagonista l'ha de dur, de nou, a Llinars. Coll Monteagudo (20I2: 54), per la seva banda, es basa, entre d'altres, en la versió I.3 de Gomis en la reelaboració literària a partir de fonts escrites titulada «La roca del Diable».

Fora de l'àrea catalana, a Espinosa, fill (I996: 378-380), números I75, I76 i I77, hi trobem tres versions del domini lingüístic espanyol que comparteixen estructura amb aquest argument descrit, però, en aquest cas, qui adopta la forma de cabra és una bruixa.

\subsection{Tipus C-113: La fondària del gorg}


(Algunes) variacions sobre el diable: una proposta de catalogació de dues llegendes satàniques

Resum:

Un home pretén mesurar la fondària d'un gorg amb una pedra lligada a un fil. Després d'amollar tota la corda, sent una veu que li diu que no trobarà el fons.

Versions:

- Amades (I950: IIO6-IIO7) núm. I506 «L'olla de les gorges» [basada en Verdaguer (I992: 245-247)];

- Coll (I989: I03) «La porta de l'infern»;

- Coll (I996: 74-76) «Espluga i Solduga»;

- Gomis (I883: I86) [Annex 2];

- GRFO (I984: I87-I88) núm. I36 «El castell de l'envestida i el gorg de la Trapa»;

- GRFO (I984: I88) núm. I37 «La foradada»;

- Maspons (1952: 43-48);

- Milà i Fontanals (Paloma I976: I6) «Residencias de los demonios y encantados. Gorg Negre»;

- Romeu (I993: I24) núm. 59 (a) (b) (c);

- Roviró (2000: 43) «Mesurar el fons del gorg Negre»;

- Torres (2003: IO9) «El pastor que volia saber la fondària del gorg de la Llana»;

- Verdaguer (I992: 245-247; 2003: 624-625) «Les Gorgues» [base d'Amades];

- Verdaguer (I992: 356-358; 2003: 655) «Gorg Bufa-roc»;

- Vinyeta (I979: 22-23) «Les pregoneses de Les Gorgues».

La versió de Gomis d'aquesta llegenda satànica coincideix amb catorze versions catalanes més, fet que justifica la creació del nou tipus. La intenció d'aquesta llegenda satànica és fer notar als humans la presència del diable. Segons conta Gomis, la seva versió és de procedència oral ja que la recull de boca del guia que li fa la visita en la seva excursió a Dosrius.

Les versions de Coll (I989: IO3), Maspons (I952: 43-48), Romeu (I993: I24) i una de Verdaguer (I992: 356-358) han estat assenyalades per Pujol (I994: 50; 2003: 295) que dóna les claus d'interpretació de l'escenari on es desenvolupa aquest argument:

Els gorgs/estanys (sovint amb noms significatius: els nombrosíssims gorgs Negres, gorgs o estanys del Diable, gorgs dels Banyuts, gorgs de les Donzelles, etc.) fascinen i terroritzen igualment a través del diable i de les encantades, que fan valer una mena de majestas satànico-demònica: el gorg és insondable i fascinant, i qui pretén desafiar-ne el mysterium s'exposa a patir les conseqüències del seu agosarament (Pujol I994: 50; 20I3: 295).

A més d'aquestes versions indicades per Pujol, en localitzo deu més. Amades (I95O: IIO6-IIO7) pren com a base una versió de Verdaguer (I992: 245-247; 2003: 655) per a redactar la que publica a la Rondallística, en una mostra més de la dependència del folklorista barceloní respecte d'altres fonts anteriors a ell. Pujol ja indicava a la presentació de la seva tesina de llicenciatura dedicada a la catalogació de rondalles catalanes com la presència de referències al corpus d'Amades es produïa únicament en absència d'altres fonts perquè: 
Gosaria dir que almenys el 60\% o el 70\% (si no faig curt) de les seves rondalles meravelloses no són més que purs i simples re-tellings o resums dels rondallistes anteriors a ell, especialment Maspons, Bertran, Alcover i Serra i Boldú, o, en el millor dels casos versions obtingudes per contaminació amb les d'ells (Pujol I982: xi).

Posteriorment, Carme Oriol va recatalogar les rondalles d'Amades a la seva tesina de llicenciatura, dedica a les rondalles d'Amades (Oriol I984), indicant també aquestes dependències. Així:

L'estudi del corpus rondallístic d'Amades permet observar que pràcticament un 50\% d'aquestes relats presenten coincidències estructurals significatives (en major o menor grau segons les versions) amb rondalles anteriorment publicades [...] Els repertoris més utilitzats per Joan Amades són, per ordre d'importància, els dels folkloristes: A. M. Alcover, F. Maspons i Labrós, P. Bertran i Bros, V. Serra i Boldú, A. Ferrer i Ginard, A. Capmany, J. Verdaguer, M. Milà i Fontanals, l'Arxiduc Lluís Salvador, E. Caseponce, P. E. Guarnerio, i A. Useri (Oriol I999: 292).

A Oriol-Pujol i al RondCat aquestes dependències s'assenyalen utilitzant les indicacions «Base de» $\mathrm{i}$ «Basada en» a les dues versions implicades (la d'Amades i la de la font en què es basa), criteri que també adopto aquí.

Coll recull dues versions d'aquest tipus. La que porta per títol «Espluga i Solduga» (I996: 74-75) és més llarga i inclou l'episodi descrit prèviament al recull Quan Judes era fadrí i sa mare festejava (I989: I03). Sí que observem diferències en la veu que surt del fons del gorg (en aquest cas, del mateix pastor). En la primera versió hi llegim: «No cal que us ascurroneu astirant, perquè les de dintre poden més que vatres!»; i en la segona: «No cal que estireu, que aquí baix hi ha més dimonis tirant, que cabells no tinc al cap».

La versió recollida a Rupit el Io de juliol de i98I pel Grup de Recerca Folklòrica d'Osona titulada «El castell de l'envestida i el gorg de la Trapa» (I984: I87-I88) l'explica en Pere Font i està protagonitzada pel dimoni i per sant Miquel. Segons conta aquest informant, és sant Miquel qui vol mesurar la fondària del gorg, perseguint el dimoni que s'hi havia llençat. L'altra versió del Grup de Recerca Folklòrica d'Osona (I984: I88), recollida també a Rupit el 23 de juliol de I98I, l'explica en Joan Balmes. En aquest cas, la veu que surt de la Foradada diu «Tira Serres, tira Ententes i tira Campàs, que encara el cul no arribaràs!».

Maspons (I952: 43-48), per la seva part, situa l'acció al «Gorg de les Donzelles». Una pastora cau al gorg, seduida per «una veu humana, fresca i clara, i tan sonora que no semblava sinó cant de sirena» que hi surt del fons. El ramat que l'acompanya es converteix en pedra un cop ella desapareix. El color particular de l'aigua d'aquest gorg i la forma estranya de les pedres que el voregen (el ramat), fa que tothom estigui temptat d'acostar-s'hi i veure quina fondària té el gorg.

Per això es conta que moltes vegades, si algú hi ha amollat fil o cànem amb una pedra al capdavall per a arribar al fons, per més fusades que hi hagi tirat, mai ha pogut aconseguir-ho, ans al contrari, sempre una veu li va cridant: -No n'hi ha prou encara (Maspons I952: 47).

La versió de Milà i Fontanals (editada per Paloma 1976: I6) està protagonitzada per dos pagesos, el de Guiteras i el del Campàs d'Orist, que han d'anar a Vic a recollir més cordes per arribar al fons del gorg Negre. No tenen èxit i «una voz de tru- 
eno que sale del profundo» els diu: «Tira tira Guiteras / Tira tira Campàs / Que ab altres tantas / No hi arribaràs». Milà i Fontanals anota una variant: «Descabdella que descabdellaràs / Que ab altres tantas no hi arribaràs». Romeu i Figueras (I993: I24) es fa ressò d'aquesta història en tres llocs diferents: (a) el Gorg del Dimoni, a Pibernat (Sant Julià de Vallfogona); (b) el Gorg dels Banyuts, de Mataplana, a Gombrèn; (c) a Vilalba, també a Sant Julià de Vallfogona.

La versió de Roviró (2000: 43) també està protagonitzada per una pastora que, de l'espant que té quan sent la veu que crida «Fila que filaràs, que mai al cul no arribaràs!», llença el fil i el fus que havia agafat per a mesurar la fondària. Fins i tot, es diu que «durant molt de temps van surar per sobre el gorg», com a testimoni d'aquest fet.

Torres (2003: I09) recull d'un pastor de Cabanes la mateixa història, situada en aquest cas al gorg de la Llana. En aquesta versió, el pastor protagonista queda traumatitzat en sentir la veu del fons $\mathrm{i}$ «des d'aquell dia sempre més va tenir una tremolor a la mà que havia aguantat el cordill».

A més de la versió ja esmentada de Verdaguer (I992: 245-247; 2003: 624-625) que Amades utilitza com a base, als seus textos rondallístics en trobem una altra, titulada «Gorg Bufa-roc» (I992: 356-358; 2003: 655) i situada «al torrent del Brescany, que mor al riu d'Agrefull, afluent del Tec» (Verdaguer I992: 356, nota 24).

La versió de Vinyeta (I979: 22-23), titulada «Les pregoneses de Les Gorgues», està protagonitzada pels pagesos del Campàs i de les Ententes, fet que també es reflecteix en el que diu la «veu gruixuda i tenebrosa» que surt del gorg: «Tira, Ententes. / Tira, Campàs, / que amb altres tantes / no hi arribaràs!». Coincideix, d'aquesta manera amb la versió del GRFO (I984: I88) i la de Milà i Fontanals (Paloma i976: i6).

\section{Algunes reflexions finals}

La proposta de creació dels tipus C-IO3 («Dimoni, on vas?») i C-II3 (La fondària del gorg) té l'objectiu d'avançar (una mica més) en l'estudi d'aquells relats que no tenen cabuda dins l'índex internacional de tipus rondallístics ATU, en el marc del projecte de catalogació de les rondalles catalanes RondCat, dut a terme pel tàndem Oriol-Pujol.

El punt de partida és, precisament i com ja s'ha vist, l'estudi de la llegenda satànica fet per Pujol (I994; 20I3: 289-306). A partir d'algunes versions assenyalades en aquest estudi i dels comentaris sobre els arguments estudiats, s'ha estructurat la creació (i justificació) dels dos nous tipus. Les versions recollides pel folklorista Cels Gomis i Mestre han servit com a base per a localitzar més versions catalanes. Res de tot això hauria estat possible, però, sense el mestratge exercit per Josep M. Pujol i que, com és obvi, va molt més enllà d'assenyalar camins a seguir en l'estudi de la llegenda satànica a partir d'unes «Variacions sobre el diable». Aquesta proposta de catalogació de dues d'aquestes llegendes satàniques vol ser, doncs, un (modest) homenatge acadèmic a l'enyorat mestre. 


\section{Referències bibliogràfiques}

AlsinA, Neus; M. Àngels JubANy (I988): «Apunts per a una historia de Dosrius. Dosrius al primer terç de segle (I900-I933)». El Comú. Revista de Dosrius núm. 2: I4-I9.

AmADES, Joan (I950): Folklore de Catalunya: Rondallística (Rondalles-TradicionsLlegendes). Barcelona: Selecta.

- (I974): Folklore de Catalunya: Rondallística (Rondalles). Barcelona: Selecta.

Arxiduc Lluís SAlvador D’Àustria-Toscana (I895): Rondayes de Mallorca. Würzburg. [Facsímil: Arxiu de Tradicions Populars I6. Palma de Mallorca: José G. de Olañeta, I982.]

Coll, Pep (I989): Quan Judes era fadrí i sa mare festejava. Barcelona: La Magrana. [Primera edició: Barcelona: Edicions del Mall, I986.]

- (I996): Viatge al Pirineu fantàstic. Barcelona: Columna.

Coll Monteagudo, Ramon (2012): El Maresme fantàstic. Llegendes. Sant Vicenç de Castellet: Farell.

EsPINOSA, Aurelio M. (fill) (I996) [1987]: Cuentos populares de Castilla y León. Vol. I. Madrid: Consejo Superior de Investigaciones Científicas.

FERrer i GINART, Andreu (2009): Llegendes de les Balears. Edició a cura de Josep Massot i Muntaner. Barcelona: Institut Menorquí d'Estudis/Publicacions de l'Abadia de Montserrat.

GOMIS I Mestre, Cels (I883): «Encontorns de Dosrius (provincia de Barcelona)». Butlletí de l'Associació d'Excursions Catalana 6, núm. 6o (setembre i883): I86.

- (I9Iо): Zoologia popular catalana. Modismes, aforismes, creencias, supersticions, etc., etc. que sobre'ls animals hi ha a Catalunya, ab gran nombre de confrontacions. Barcelona: Tip. «L'Avenç», Centre Excursionista de Catalunya.

- (I987): La bruixa catalana. Aplec de casos de bruixeria, creences i supersticions recollits a Catalunya a l'entorn dels anys I864 a I9I5. Edició a cura de Cels Gomis i Serdañons. Barcelona: Editorial Alta Fulla.

- (2014): Zoologia popular catalana. Modismes, aforismes, creences, supersticions, que sobre els animals hi ha a Catalunya, amb gran nombre de confrontacions. La Bisbal d'Empordà: Edicions Sidillà.

[GRFO] Grup de Recerca Folklòrica d'Osona (I984): El folklore de Rupit i Pruit. Vol. II. Narracions. Vic: Eumo Editorial.

JASON, Heda (2000): Motif, type and genre: a manual for compilation of indices \& a bibliography of indices and indexing. Folklore Fellows' Communications 273. Hèlsinki: Suomalainen Tiedeakatemia.

MAspons i LABrós, Francesc de Sales (1952): Tradicions del Vallès. Pròleg de F. Maspons i Anglasell. Biblioteca Folklòrica Barcino 2. Barcelona: Barcino. [Primera edició: Barcelona: Estampa de la Renaixensa, I876.]

Mestres, Apel-les (I933): Llegendes i tradicions del Montseny. Contribució al folk-lor català. Barcelona: Salvador Bonavia, llibreter.

- (2004): Llegendes del Montseny. Selecció, introducció i notes de Carme Rubio i M. Carme Bernal. Barcelona: Publicacions de l'Abadia de Montserrat. 
(Algunes) variacions sobre el diable: una proposta de catalogació de dues llegendes satàniques

ORIOL, Carme (I984): «Aproximació a la rondallística de Joan Amades: catalogació i fonts». Tesi de llicenciatura dirigida pel Dr. Jaume Vidal. Universitat de Barcelona.

- (I999): «Les rondalles de Joan Amades i la seva relació amb fonts impreses anteriors». Estudis de Llengua i Literatura Catalanes XXXVIII. Homenatge a Arthur Terry, vol. 2: 289-3II.

OrIOL, Carme; Josep M. PUJOL (2002): «El projecte RondCat: inventari i catalogació del patrimoni rondallístic català». Revista d'etnologia de Catalunya núm. 2I (novembre 2002): I46-I55.

- (2003): Índex tipològic de la rondalla catalana. Barcelona: Generalitat de Catalunya.

- (2008): Index of Catalan Folktales. Folklore Fellows' Communications 294. Hèlsinki: Suomalainen Tiedeakatemia.

OrIOL, Carme; Emili SAMPER (eds.) (20I3): Això era i no era. Obra folklòrica de Josep M. Pujol. Tarragona: Publicacions de la Universitat Rovira i Virgili.

PALOMA, Joan-Antoni (1976): «Un curiós manuscrit del fons Milà i Fontanals de Santander, sobre supersticions i costums populars». Miscellanea Barcinonensia: revista de investigación y alta cultura $\mathrm{I} 5$, núm. XLIII: 7-58.

Pujol, Josep M. (I982): «Contribució a l'índex de tipus de la rondalla catalana». Tesi de llicenciatura dirigida pel Dr. Jaume Vidal. Universitat de Barcelona.

— (I994): «Variacions sobre el diable». Revista d'etnologia de Catalunya núm. 4 (febrer I994): 44-57.

ROMEU I FIgUERAS, Josep (I993): Materials i estudis de folklore. Estudi preliminar i índex analític de Josep M. Pujol. Barcelona: Alta Fulla.

RondCat: cercador de la rondalla catalana. Base de dades en línia. Arxiu de Folklore. Departament de Filologia Catalana de la Universitat Rovira i Virgili <http:// rondcat.arxiudefolklore.cat> [data de consulta: juliol de 20I5]

Roviró, Xavier (2000): Ioo llegendes de la plana de Vic. Sant Vicenç de Castellet: Farell.

SAMPER Prunera, Emili (20I3a): «Cels Gomis i Mestre: Biografia i narrativa folklòrica». Tesi doctoral dirigida per la Dra. Carme Oriol i Carazo i el Dr. Magí Sunyer Molné. Tarragona: Departament de Filologia Catalana de la Universitat Rovira i Virgili. Disponible en línia a <http://hdl.handle.net/Io803/IIIo95>

- (20I3b): De l'anarquisme al folklore. Cels Gomis i Mestre (I84I-I9I5). Tarragona: Publicacions de la Universitat Rovira i Virgili.

- (20I5): Les rondalles de Cels Gomis i Mestre. Edició, catalogació i estudi. Barcelona: Publicacions de l'Abadia de Montserrat.

SERRA I BOLDÚ, Valeri (I932): «Folklore de la pagesia. La cabra. Tradicions, llegendes i supersticions». Agricultura i ramaderia I6, núm. 5 (maig I932): 86-87.

- (I987): Folklore de la pagesia. Edició i estudi preliminar a cura d'Isidor Cònsul i de Ramon Miró. Barcelona: Publicacions de l'Abadia de Montserrat.

Thompson, Stith (I955-58): Motif-Index of Folk-Literature. 6 volums. Bloomington: Indiana University Press. 
TORReS, Jordi (2003): Por, màgica i tresors a la Catalunya interior. Sant Vicenç de Castellet: Farell.

UTHER, Hans-Jörg [ATU] (2004): The types of international folktales. A classification and bibliography based on the system of Antti Aarne and Stith Thompson. 3 volums. Folklore Fellows' Communications 284, 285, 286. Hèlsinki: Suomalainen Tiedeakatemia.

Verdaguer, Jacint (I992): Rondalles. A cura d'Andreu Bosch i Rodoreda. Barcelona: Barcino.

- (2003): Prosa. A cura de Joaquim Molas i d'Isidor Cònsul, amb la col-laboració de Lluïsa Plans i Girabalt, d'Andreu Bosch i Rodoreda i de Francesc Codina. Barcelona: Proa.

VinyetA, Ramon (I979): Llegendes i tradicions de la Vall del Ges i els seus contorns. Torelló: Editorial Celblau.

\section{Annex: textos de Cels Gomis i Mestre}

\section{Tipus C-103}

\section{1 «La cabra a les tradicions» [El dimoni en forma de cabra]}

Al riu Fluvià, aigües avall del pont de la carretera de Santa Coloma de Farners a Olot, i prop d'aquesta ciutat, hi ha una gorga nomenada del Dimoni, a causa del fet següent:

Una nit tornava un sastre de treballar a una casa de pagès i va trobar una cabra. Se la va carregar a coll i, en passar vora la gorga, va sentir una veu que cridava des de dins de l'aigua:

-Dimoni, on vas?

—A cavall d'aquest sastràs — va respondre la cabra, que no era altre que el mal esperit.

—Valga'm les témpores de sant Tomàs! —va cridar esfereït el sastre en sentir aquella veu, tot deixant anar la cabra.

—Et valdran si dejunades les has, i, si no, no et valdran pas — va replicar la veu de la gorga.

I com que les havia dejunades, es va veure lliure del dimoni, que es va enfonsar a l'aigua.

Gomis i Mestre, Cels (20I4): Zoologia popular catalana. Modismes, aforismes, creences, supersticions, que sobre els animals hi ha a Catalunya, amb gran nombre de confrontacions. La Bisbal d'Empordà: Edicions Sidillà, p. IO2-IO3. 
(Algunes) variacions sobre el diable: una proposta de catalogació de dues llegendes satàniques

\section{2 [El gorg dels dimonis]}

En el terme de Vilanant (Alt Empordà) hi ha un lloc anomenat gorg dels Dimonis a causa de la tradició següent:

Un sastre tornava un vespre de treballar en un mas quan tot d'un plegat se li va aparèixer un cabró. El sastre se'l carregà al coll per emportar-se'l cap a casa i, en arribar a la vora del gorg, que es troba tocant al camí, sentí una veu que del fons de l'aigua cridava:

-Satanàs, on vas?

—A cavall d'aquest sastràs —respongué el cabró.

—Bona festa que faràs! —replicà la veu del gorg.

—Valga'm les témpores de sant Tomàs! —exclamà esfereït el sastre en sentir això tot llençant el cabró dintre del gorg.

—Bé et valdran si dejunades les has i, si no, no et valdran pas! —cridà de nou la veu del gorg.

I, com que les havia dejunades, li valgueren, i es va veure lliure del dimoni i va poder arribar sense cap més entrebanc a casa seva.

(Vilanant, I883).

Gomis i Mestre, Cels (1987): La bruixa catalana. Aplec de casos de bruixeria, creences $i$ supersticions recollits a Catalunya a l'entorn dels anys I864 a I9I5. Barcelona: Editorial Alta Fulla, p. 94.

\section{3 [La cabra negra perduda]}

Anant a deshora de la nit de Dosrius a Llinars, un veí d'aquest darrer poble trobà en el seu camí una cabra negra que semblava perduda i se la carregà al coll tot content de la troballa. Mes vet aquí que, en arribar a la roca del Diable, ${ }^{9}$ va sentir una veu que deia:

-Dimoni xic, on vas?

- A cavall d'en Jaumàs — respongué la cabra.

En sentir que la cabra parlava, el viador la va deixar anar i va arrencar a córrer tot dient:

-Fes-te refotre! No et duré pas a Llinars.

(Dosrius, I882).

Gomis i Mestre, Cels (1987): La bruixa catalana. Aplec de casos de bruixeria, creences $i$ supersticions recollits a Catalunya a l'entorn dels anys I864 a I9I5. Barcelona: Editorial Alta Fulla, p. 94.

9. Gomis] Vegeu la descripció d'aquesta roca al meu article «Encontorns de Dosrius», Butlletí de l'AEC, any I883, p. I82-I87 (Gomis 1987: 94). 


\section{4 [La cabra a coll]}

A Xerta, a la Ribera d'Ebre, el dimoni es descarà encara més, puix que es va atrevir a presentar-se dins de la vila.

Un fadrí que retirava molt tard de festejar amb la seva minyona va trobar una nit una cabra al mig de la plaça. Se la va carregar al coll i, en anar a trucar a la porta de casa seva, va sentir que la cabra li deia:

-Deixa'm anar, que prou m'has portat!

I el fadrí la deixà anar tot ple de por, i mai més no es va atrevir a retirar tard. (Xerta, I885).

Gomis i Mestre, Cels (1987): La bruixa catalana. Aplec de casos de bruixeria, creences i supersticions recollits a Catalunya a l'entorn dels anys I864 a 19I5. Barcelona: Editorial Alta Fulla, p. 95.

\section{Tipus C-113}

\section{[La veu del sot d'aigua]}

Pel camí, mon guia em contà que a Gualba de Dalt hi ha un gran sot d'aigua, tan fondo, que ningú n'ha pogut midar la fondària. Un dia, afegí mon guia, hi anà un home amb un cordill de més de dues-centes canes, hi lligà un roc i començà a fer baixar lo cordill dins del sot. Ja quasi el tenia tot a baix quan va sentir una veu que, sortint del fondo de l'aigua, li deia:

Ja pots cordill tirar, que, per més que n'hi tiris, lo fons no trobaràs.

Al sentir aquella veu, l'home agafà por i fugí d'allí corrents.

Gomis i Mestre, Cels (I883): «Encontorns de Dosrius (provincia de Barcelona)». Butlletí de l'Associació d'Excursions Catalana 6, núm. 6o (setembre, I883): I86. 